\title{
Pulsed electron avalanche knife: new technology for cataract surgery
}

\author{
Siegfried G Priglinger, Daniel Palanker, Claudia S Alge, Thomas C Kreutzer, Christos Haritoglou, \\ Martin Grueterich, Anselm Kampik
}

Br J Ophthalmol 2007;91:949-954. doi: 10.1136/bjo.2006.109546

See end of article for authors' affiliations

Correspondence to:

Dr S G Priglinger,

Department of

Ophthalmology, Ludwig-

Maximilians-University,

Munich, Mathildenstr 8 ,

80336 Munich, Germany

siegfried.priglinger@med.

uni-muenchen.de

Accepted 2 January 2007
Background: The pulsed electron avalanche knife (PEAK-fc) is a new pulsed electrosurgical device that allows for precise, "cold" and traction-free tissue dissection.

Aim: To evaluate the surgical applicability, safety and potential complications of PEAK- $f_{c}$ in complicated cataract surgery.

Methods: The study included five children with congenital cataracts, two patients with advanced senile cataracts, six adults with mature cataracts, three of them with posterior iris synechia, three patients with posttraumatic cataracts with zonulolysis, one patient with intumescent traumatic cataract and three patients with massive anterior capsule opacification. Anterior and posterior capsulotomies, iris synechiolysis, dissection of anterior capsule opacification and fibrotic scar tissue were performed. PEAK-fc was set at voltages of 500$700 \mathrm{~V}$, pulse duration of $0.1 \mathrm{~m}$ and repetition rate of $40-100 \mathrm{~Hz}$.

Results: Anterior and posterior capsulotomies were successfully and safely performed in all eyes. The edges of capsulotomies appeared sharp, showing only limited collateral damage. PEAK-fc worked best by just gently touching the capsule, thereby avoiding tractional forces or pressure on the lens capsule. Posterior iris synechiae could be released and anterior capsule opacification was dissected without complications.

Conclusions: PEAK-fc is a very helpful cutting device for complicated cases of cataract surgery, especially for mature and congenital cataracts, traumatic zonulolysis or anterior segment complications after intraocular inflammation.
$\mathrm{T}$ he pulsed electron avalanche knife (PEAK-fc, Carl Zeiss Meditec, Jena, Germany) is a new electrosurgical device, which has recently been introduced for "cold" and traction-free dissection of tissue in liquid medium. ${ }^{1-4}$ Similar to dielectric breakdown-based short pulsed laser technology, PEAK-fc works by induction of plasma in the conductive medium or in tissue generated by microsecond pulses of high electric field. Short (up to $100 \mu \mathrm{s}$ ) bursts of electric pulses rapidly vaporise and ionise liquid and tissue in close proximity to the $50 \mu \mathrm{m}$ wire microelectrode, leading to ablation or dissection of the surrounding tissue. As PEAK-fc uses pulses not exceeding $100 \mu \mathrm{s}$ in duration, the heat diffuses to the surrounding tissue only up to $7 \mu \mathrm{m}$, thereby inducing only a little thermal collateral damage. The PEAK-fc technique is therefore referred to as "cold" cutting. ${ }^{1-4}$ The heat confinement by use of short-pulse plasma-mediated discharges distinguishes PEAK technology from the conventional continuous radiofrequency devices such as Wet-Field Hemostatic Coagulator (Medtronic, Jacksonville, Florida, USA), DIACAPSUTOM (ERBE Elektromedizin GmbH, Tübingen, Germany) or Fugo Blade (MediSURG, Norristown, Pennsylvania, USA).

We recently showed the multifunctional applicability of PEAK-fc in vitreoretinal surgery. ${ }^{5}$ It was successfully used for a variety of surgical manoeuvres commonly encountered in patients undergoing vitreoretinal surgery. Advantages of this new technology include sharply defined transection and incision of epiretinal membranes, fine coagulation of vascularised epiretinal tissue during surgery for diabetic traction detachment and traction-free dissection of attached or elevated retina. ${ }^{5}$ In these studies PEAK-fc has proven to be a promising cutting device for intraocular surgery, allowing for a higher level of microsurgical precision. ${ }^{56}$

On the basis of promising experiences with PEAK-fc in vitreoretinal surgery, ${ }^{56}$ in the present study we evaluated the applicability of this new microsurgical tool for anterior segment surgery. The safety and efficacy of PEAK-fc were evaluated in various surgical manoeuvres in patients undergoing surgery for capsulotomy in paediatric cataracts, mature or post-traumatic cataracts with zonulolysis, posterior iris synechiae after uveitis and massive anterior capsule opacification.

\section{MATERIALS AND METHODS}

PEAK-fc - second version

In contrast to the first version of PEAK, which was operating with sub-microsecond pulses of 3-6 kV,,$^{1-3}$ the advanced PEAKfc (fig 1) operates at much lower voltages (300-700 V) and utilises much longer pulses of about $100 \mu \mathrm{s}$, consisting of a burst of several tens of biphasic (alternating current) "minipulses", each of which is $1-2 \mu$ s in duration (corresponding to mini-pulse frequencies of up to $300 \mathrm{kHz}$ ). The cutting part of the PEAK-fc probe is a protruding tungsten wire with a diameter of $50 \mu \mathrm{m}$, extending from the glass insulator by $0.6 \mathrm{~mm}$ (fig 1). In addition to "cold" cutting, a coagulation mode has been integrated.

In the present study, PEAK-fc parameters were set as follows: pulse repetition rate $40-100 \mathrm{~Hz}$, pulse duration $100 \mu$ s and number of "minipulses" per pulse 60. Amplitude of the biphasic voltage was varied within a range of 500-700 V, corresponding to pulse energies of $6-10 \mathrm{~mJ}$. With a pulse repetition rate of $100 \mathrm{~Hz}$, it corresponds to an average power of 60-100 $\mathrm{mW}$. The average power during coagulation was $2-3 \mathrm{~W}$. Table 1 shows the specific parameters selected for the individual manoeuvres.

Abbreviations: CCC, continuous curvilinear capsulorhexis; PEAK-fc, pulsed electron avalanche knife 


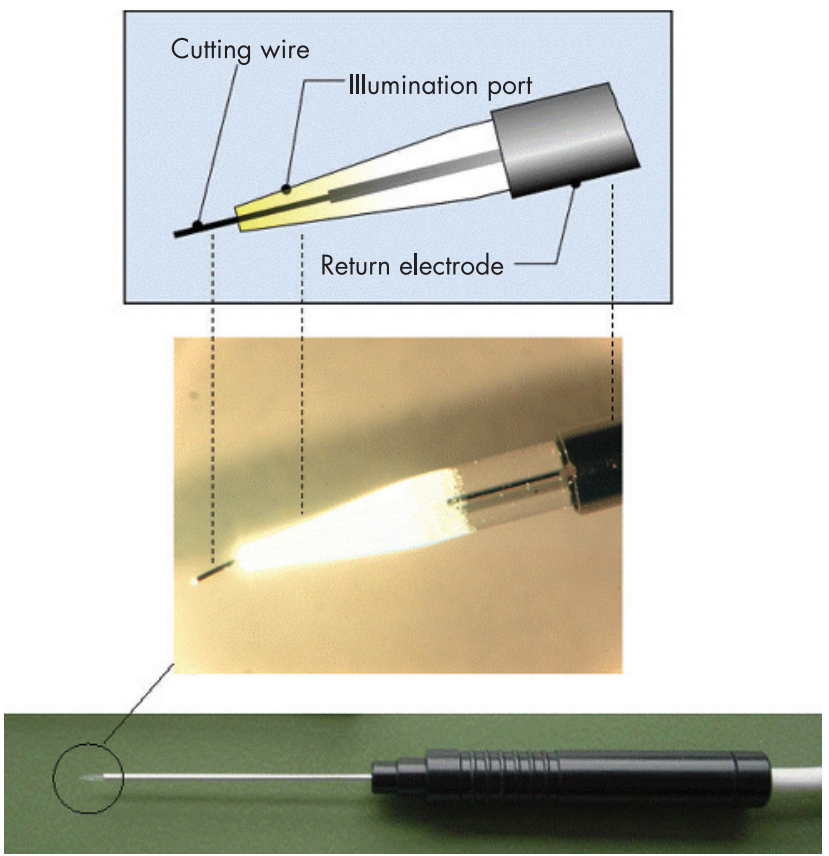

Figure 1 Diagram of pulsed electron avalanche knife (PEAK- $\left.f_{c}\right)$ probe. The cutting part of the PEAK-fc probe is a protruding tungsten wire with a diameter of $50 \mu \mathrm{m}$. The wire used in this study extends from the glass insulator to $0.6 \mathrm{~mm}$. The PEAK-fc operates at voltages from 300 to $700 \mathrm{~V}$, with a pulse of about $100 \mu \mathrm{s}$ in duration, consisting of a burst of several tens of microsecond-long "mini-pulses".

\section{Patients and surgical approach}

Twenty patients were consecutively included in this study. Patients were selected on the basis of potential suitability for the surgical manoeuvres that could benefit from the application of PEAK-fc. Surgery was performed after obtaining written informed consent for the intraoperative use of PEAK-fc. Consent was taken from the patients themselves, or, minors, from parents or legal guardians. Methods for securing human tissue were humane, included proper consent and approval, complied with the principles of the Declaration of Helsinki, and were approved by the local ethics committee. Follow-up visits were set at 1 week, 4 weeks, 3 and 6 months postoperatively. The study was monitored by an external review board. Exclusion criteria were history of glaucoma, visual acuity of $<20 / 800$ in the fellow eye or a medical history requiring systemic anticoagulation.

We included one eye of each patient (table 2). Ten men and ten women with a mean (range) age of 46.0 (2-81) years were enrolled in the study. Preoperative diagnosis included five children with congenital cataracts, two patients with advanced senile cataracts, six patients with mature cataracts, three of them with posterior iris synechia, three patients with posttraumatic cataracts with zonulolysis, one patient with posttraumatic intumescent cataract, two patients with anterior capsule opacification after cataract surgery and one patient with massive fibrosis covering the iris, pupil and nearly the whole trabecular meshwork.

All patients underwent complete ophthalmological examinations including visual acuity testing (Snellen), slit-lamp examination, intraocular pressure measurement and fundus biomicroscopy during the follow-up examinations at day 3 , 4 weeks, 10 weeks, 3 and 6 months postoperatively. To rule out potential adverse effects, corneal endothelial cell counts were performed.

Congenital cataracts were extracted by microincisional lens aspiration using the Megatron S3 vip (Geuder, Heidelberg, Germany) in general anaesthesia. The anterior chamber was expanded with a viscoelastic substance (Healon, AMO, Santa Ana, California, USA). For anterior capsulotomy, the PEAK-fc probe was then slowly moved along the capsule in a circular manner (6.0 $\mathrm{mm}$ in diameter), with a velocity of approximately $1 \mathrm{~mm} / \mathrm{s}$, and just gently touching the capsule, thereby avoiding tractional forces and pressure on the lens capsule. After lens aspiration and injection of viscoelastic material, one of the clear cornea incisions was enlarged to $2.0 \mathrm{~mm}$ and the intraocular lens (AcriSmart, AcriTec, Berlin, Germany) was inserted.

For senile and mature cataracts, cataracts with zonulolysis and intumescent traumatic cataract, anterior capsulotomy with PEAK-fc was performed as described above. However, cataract surgery differed with respect to the access and phako technique: a superior clear or sclerocorneal incision was created. Cataract extraction was performed using the divide and conquer technique. ${ }^{7}$ Trypan blue (vision blue, DORC, Zuidland, Netherlands) was used to enhance visualisation of the anterior lens capsule in mature cataracts. ${ }^{8}$ '

Three patients, two of them with long-lasting uveitis and the remaining one with a history of trauma, besides advanced cataract formation, were having massive posterior iris synechiae. Superior sclerocorneal incision was performed with a diamond blade and $2.75 \mathrm{~mm}$ steel keratome (Alcon, Fort Worth Texas, USA), and the anterior chamber expanded with a viscoelastic substance (Healon, AMO, Santana, California, USA). As iris synechiae in these cases were too tight to be loosened by a conventional "Binkhorst" iris spatula (Geuder, Heidelberg Germany) or high-frequency capsulotomy, PEAK-fc was applied. The PEAK-fc parameters were slowly increased until the desired cutting effect was observed, thereby allowing the probe to be gently moved underneath the iris.

Excision of anterior capsule opacification was performed after formation of two opposite stab incisions at the limbus and expansion of the anterior chamber with a viscoelastic substance (Healon, AMO). The PEAK-fc probe was then slowly moved along the anterior capsule in a circular manner $(7.0 \mathrm{~mm}$ in diameter) with a velocity of approximately $1 \mathrm{~mm} / \mathrm{s}$, just gently touching the capsule without induction of tractional forces.

Excision of massive fibrotic scar tissue on the iris and in the pupil was performed after formation of two opposite stab incisions at the limbus and padding the anterior chamber with a viscoelastic substance (Healon). After excision of the fibrotic membrane in the pupil, tightly attached scar tissue covering the whole iris was carefully separated by accurate dissection of the extensive posterior iris synechiae.

Table 1 Pulsed electron avalanche knife parameters for each manoeuvre performed

\begin{tabular}{lllll}
\hline Manoeuvre & $\begin{array}{l}\text { Voltage } \\
(\mathrm{V})\end{array}$ & $\begin{array}{l}\text { Repetition } \\
\text { rate }(\mathrm{Hz})\end{array}$ & Minipulses/pulse & $\begin{array}{l}\text { Pulse duration } \\
(\boldsymbol{\mu})\end{array}$ \\
\hline Anterior and posterior capsulotomy & 600 & $60-100$ & 60 & 100 \\
Synechiolysis & 500 & $40-60$ & 60 & 100 \\
Dissection of anterior capsule phimosis/scar tissue & 700 & $80-100$ & 60 & 100 \\
\hline
\end{tabular}


Table 2 Pulsed electron avalanche knife manoeuvres

\begin{tabular}{|c|c|c|c|c|c|c|}
\hline Patient & Age (years) & Sex & Eye & Diagnosis & Operation & PEAK maneuver \\
\hline 1 & 2.5 & $\mathrm{~F}$ & $\mathrm{R}$ & Congenital cataract & MICS, IOL & $\begin{array}{l}\text { Anterior and posterior } \\
\text { capsulorhexis }\end{array}$ \\
\hline 2 & 3 & $\mathrm{~F}$ & $\mathrm{R}$ & Congenital cataract & Phaco, IOL & Anterior capsulorhexis \\
\hline 3 & 2 & $\mathrm{~F}$ & $\mathrm{~L}$ & Congenital cataract & MICS, IOL & Anterior capsulorhexis \\
\hline 4 & 3 & M & $\mathrm{R}$ & Congenital cataract & MICS, IOL & $\begin{array}{l}\text { Anterior and posterior } \\
\text { capsulorhexis }\end{array}$ \\
\hline 5 & 2 & $M$ & $\mathrm{~L}$ & Congenital cataract & MICS, IOL & Anterior capsulorhexis \\
\hline 6 & 75 & M & $\mathrm{L}$ & Hypermature cataract & Phaco, IOL & Anterior capsulorhexis \\
\hline 7 & 61 & M & $\mathrm{R}$ & Hypermature cataract & Phaco, IOL & Anterior capsulorhexis \\
\hline 8 & 78 & M & I & Hypermature cataract & Phaco, IOL & Anterior capsulorhexis \\
\hline 9 & 81 & $\mathrm{~F}$ & L & Hypermature cataract, posterior iris synechiae & Synechiolysis, Phaco, IOL & $\begin{array}{l}\text { Synechiolysis, anterior } \\
\text { capsulorhexis }\end{array}$ \\
\hline 10 & 75 & $\mathrm{~F}$ & $\mathrm{R}$ & Mature cataract, posterior iris synechiae (uveitis) & Synechiolysis, Phaco, IOL & $\begin{array}{l}\text { Synechiolysis, anterior } \\
\text { capsulorhexis }\end{array}$ \\
\hline 11 & 18 & $\mathrm{~F}$ & $\mathrm{R}$ & Mature cataract, posterior iris synechiae (uveitis) & Synechiolysis, Phaco & $\begin{array}{l}\text { Synechiolysis, anterior } \\
\text { capsulorhexis }\end{array}$ \\
\hline 12 & 29 & M & $\mathrm{R}$ & Traumatic cataract, lentodonesis & Phaco, IOL & Anterior capsulorhexis \\
\hline 13 & 62 & $\mathrm{~F}$ & $\dot{L}$ & Traumatic cataract, lentodonesis & Phaco, IOL & Anterior capsulorhexis \\
\hline 14 & 54 & $M$ & L & Traumatic intumescent cataract, lentodonesis & Phaco, IOL & Anterior capsulorhexis \\
\hline 15 & 34 & $\mathrm{~F}$ & $\mathrm{R}$ & Traumatic intumescent cataract & Phaco, IOL & Anterior capsulorhexis \\
\hline 16 & 75 & $\mathrm{~F}$ & L & Anterior capsular phimosis & See procedure & $\begin{array}{l}\text { Dissection of anterior capsule } \\
\text { phimosis }\end{array}$ \\
\hline 17 & 66 & M & L & Anterior capsular phimosis & See procedure & $\begin{array}{l}\text { Dissection of anterior capsule } \\
\text { phimosis }\end{array}$ \\
\hline 18 & 55 & $\mathrm{~F}$ & $\mathrm{R}$ & Massive anterior chamber fibrosis & See procedure & Dissection of scar tissue \\
\hline 19 & 70 & M & $\mathrm{L}$ & Advanced senile cataract & Phaco, IOL & $\begin{array}{l}\text { Completion of circular } \\
\text { capsulorhexis after removal of } \\
\text { synechiae }\end{array}$ \\
\hline 20 & 75 & M & $\mathrm{R}$ & Advanced senile cataract & Phaco, IOL & $\begin{array}{l}\text { Radial rip due to conventional } \\
\text { CCC }\end{array}$ \\
\hline
\end{tabular}

CCC, continuous curvilinear capsulorrhexis; F, female; IOL, intraocular lens; L, left, M, male; MICS, microincision cataract surgery; PEAK, pulsed electron avalanche knife; $R$, right.

All manoeuvres were recorded on videotape, permitting documentation of the efficacy and possible complications.

\section{RESULTS}

A total of 20 consecutive patients were treated with PEAK-fc. In each manoeuvre, PEAK-fc was initially set at the values that had been determined in animal and in vitro studies as safe and efficient for dissection with only minimal collateral damage. ${ }^{5}$ Parameters were increased until the desirable tissue effect was observed. Typical effective settings used for the respective manoeuvre are referred to in table 1.

Anterior capsulotomy was performed successfully in 15 eyes of 15 patients (fig 2). These included patients having congenital cataract $(n=5)$, mature cataract $(n=6)$ or post-traumatic cataract $(n=4)$. In two patients with congenital cataract, a posterior capsulotomy and anterior vitrectomy were additionally performed.

In comparison to dissection of retinal tissue, ${ }^{5}$ a higher voltage level and increased repetition rate $(600 \mathrm{~V}$, repetition rate $60-100 \mathrm{~Hz}$ ) were used, resulting in most effective cutting. Successful performance of capsulotomy required a slow movement of the probe along the capsule in a circular manner with a velocity of approximately $1 \mathrm{~mm} / \mathrm{s}$. The lens capsule was just gently touched, thereby avoiding tractional forces and pressure on the capsule. PEAK-fc cuts showed sharp edges with hardly visible whitening, indicating very little collateral damage (fig 2B). Even in cases of massive pigment deposition after removal of iris synechiae,
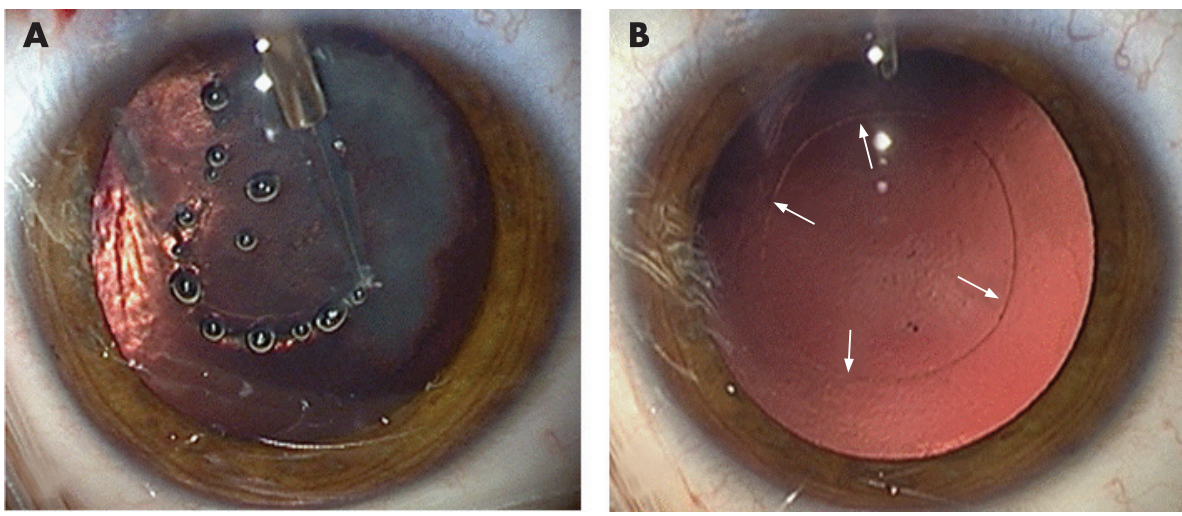

Figure 2 Capsulotomy. (A) Patient 12 presenting with traumatic cataract and phacodonesis. Anterior capsulotomy with a pulsed electron avalanche knife (PEAK-fc) at a voltage level of $500 \mathrm{~V}$ and with a repetition rate of $100 \mathrm{~Hz}$ was performed. Slow probe movement along the surface capsule with a velocity of approximately $1 \mathrm{~mm} / \mathrm{s}$ was required for tractionless dissection of the anterior capsule. (B) Capsulotomy performed with PEAK-fc reveals very sharp edges. Hardly visible whitening (indicated by arrows) indicates very little collateral damage. 

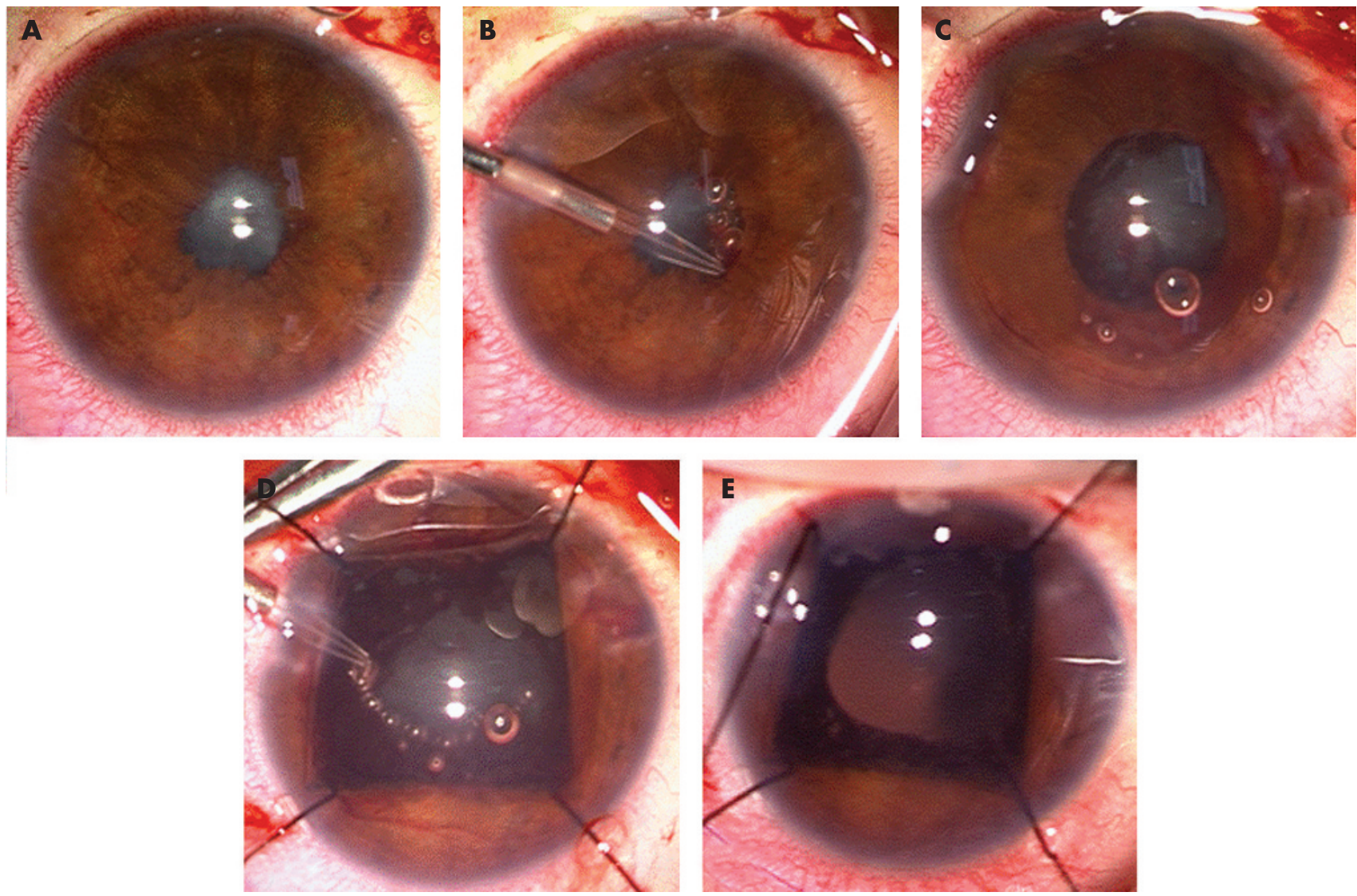

Figure 3 Synechiolysis, capsulotomy. (A) Patient 9 with chronic uveitis for many years. He presented with mature cataract and posterior iris synechiae. Dissection of the synechiae with conventional instruments was not successful. (B) Pulsed electron avalanche knife (PEAK-fc) allowed for selective tissue dissection without affecting adjacent tissues such as lens capsules or iris vessels. (C) After separation of the iris with PEAK-fc, the anterior chamber was again padded with viscoelastic material. Massive iris pigment deposition made a conventional continuous curvilinear capsulorhexis impossible. (D) Capsulotomy performed with PEAK-fc using a voltage level of $500 \mathrm{~V}$ and a repetition rate of $100 \mathrm{~Hz}$. (E) Note the sharp edges of the lens capsulotomy. Because of potential inflammatory response, primary implantation of an intraocular lens was resigned.
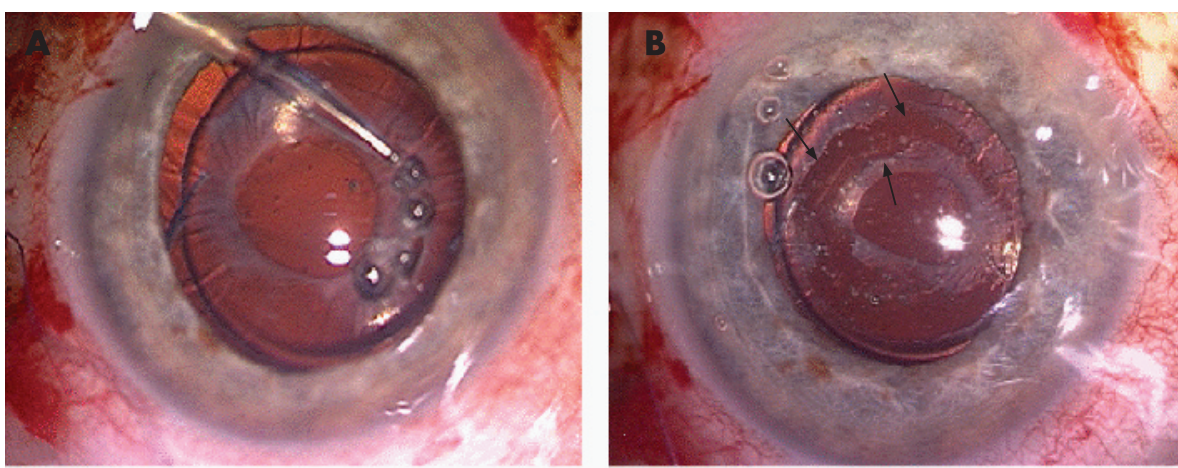

Figure 4 Anterior capsule phimosis. (A) Patient 16 presenting with distinct anterior capsule opacification. (B) Pulsed electron avalanche knife (PEAK-fc) offers a safe and easy way to remove even tightly attached tissue on intraocular lens (IOL) surface. The anterior capsule opacification has been circularly excised without any damage to the intraocular structure or $\mathrm{IOL}$ material. (C)

Appearance after removal of the dissected tissue. Arrows indicate the edge of the cut.

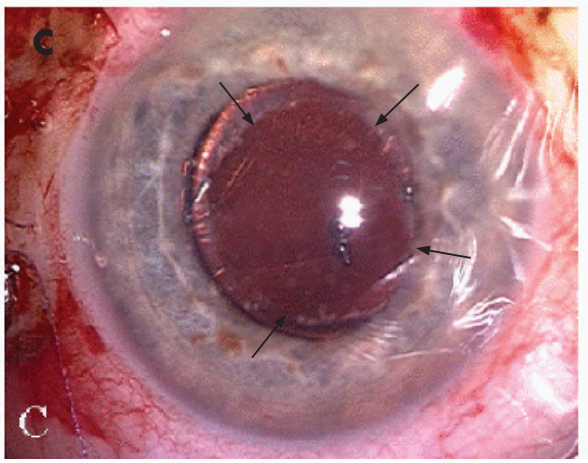



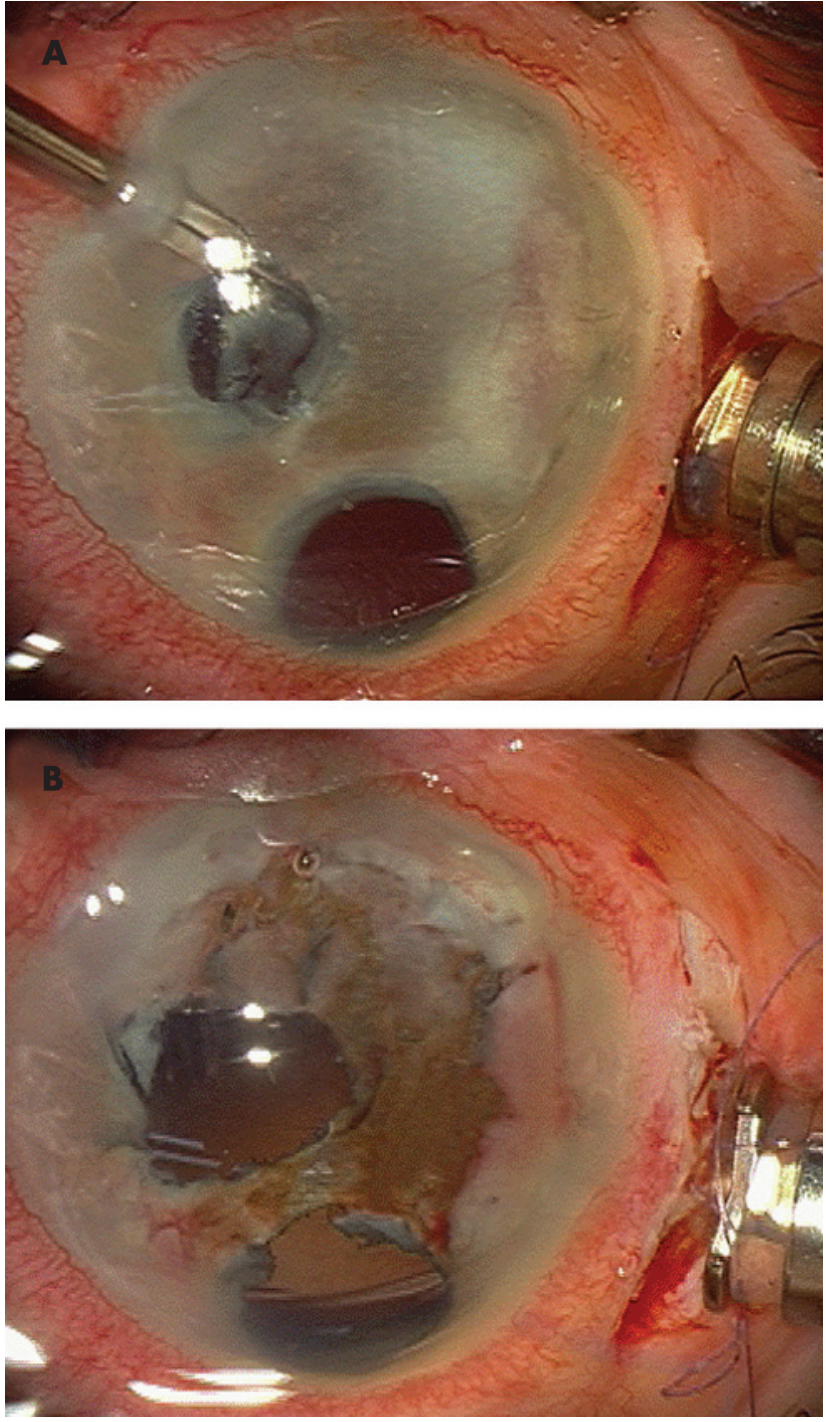

Figure 5 Excision of fibrotic scar tissue. (A) Patient 18 presenting with massive fibrotic scar tissue after several intraocular surgeries. The scar tissue covered the pupil and iris. Gonioscopy revealed only residual parts of the visible trabecular meshwork. (B) A Large amount of the scar tissue had been successfully excised with pulsed electron avalanche knife. After surgery, the anterior segment revealed a regular pupil and nearly clean iris.

continuous circular capsulotomies could be performed (fig 3C).

In two cases, surgeons initially failed to successfully perform a continuous curvilinear capsulorhexis with a capsulorhexis forceps (table 2). Capsulorhexis margins showed an extensive radial rip with impending injury of the posterior capsule. Subsequently, PEAK-fc was applied and a circular anterior capsulotomy could be successfully completed, thereby avoiding a tear in the posterior capsule and allowing for an intraocular lens implantation into the capsule bag.

PEAK-fc was also successfully used for the separation of posterior iris synechiae (fig 3) in a patient with a history of severe post-traumatic inflammation and in two patients with chronic uveitis for many years. All of them presented with mature cataracts and an iris that was completely tightly attached to the lens capsule. Attempts to loosen these synechiae with conventional instruments were unsuccessful (fig 3A). However, with PEAK-fc, these tight synechiae could be released without damaging the lens capsule (fig 3B,C). Only a minimal bleeding occurred in iris vessels, which stopped spontaneously. After successful synechiolysis, surgery was continued, with capsulotomy performed using PEAK-fc in all cases. In cases of uveitis, the lens capsules were covered with different amounts of residual iris pigment, which might have made a conventional continuous curvilinear capsulorhexis very difficult or even impossible. In all these cases, PEAK-fc allowed for a round continuous capsulotomy (fig 3D,E).

Removal of anterior capsule opacification (fig 4) was performed successfully in two cases. Here, PEAK-fc parameters were set to $700 \mathrm{~V}$, and pulse repetition rate to $80-100 \mathrm{~Hz}$. After filling the anterior chamber with viscoelasic material, anterior capsule opacifications were circularly excised without any traction and then removed with forceps.

Excision of massive scar fibrotic tissue on iris and in the pupil (fig 5) was performed after formation of two opposite stab incisions at the limbus and padding the anterior chamber with a viscoelastic substance (Healon). Scar tissue was carefully separated from the iris by undermining the fibrotic tissue. PEAK-fc allowed for selective tissue dissection without affecting the iris. After surgery the eye had a regular pupil and an almost clean iris. Removal of the scar tissue required higher energy levels (up to $700 \mathrm{~V}$ ).

Limitation: Gas bubbles (containing oxygen, hydrogen and air), similar to those seen during conventional diathermy, sometimes slightly impaired visualisation during surgery. However, for the PEAK-fc parameters used, the amount of bubbles was reduced to a minimum and controlled cuts could be performed in all surgical procedures without stopping surgeries for the removal of gas bubbles.

No PEAK-fc-related complication occurred during surgeries. Ophthalmological examinations showed regular diagnostic findings during the entire follow-up period. Postoperative changes of endothelial cell counts (mean (SD) $8.5(2.1) \%$ ) were similar to those seen in conventional cataract surgery. ${ }^{10}{ }^{11}$ During the follow-up period, no cystoid macular oedema occurred in any of the patients, and the mean (SD) gain in visual acuity was 5.6 (3.3) Snellen lines.

\section{DISCUSSION}

In this study, we report the initial clinical experience with the new "cold-cutting" device PEAK-fc for manoeuvres in cataract and advanced anterior segment surgery. PEAK-fc was successfully used for capsulotomies in congenital cataracts, mature and intumescent cataracts, and posttraumatic cataracts with zonulolysis, for separation of massive posterior iris synechiae and dissection of anterior capsule opacification.

In cases of mature cataract, post-traumatic cataract, pseudoexfoliation with weak zonules and in congenital cataract, ${ }^{12}{ }^{13}$ the risk of peripheral extension of the continuous curvilinear capsulorhexis $^{14}$ is markedly increased. In contrast with CCC, which usually exerts a certain degree of traction on the capsule, thus increasing the risk of peripheral extension of the cut, PEAK-fc dissects tissue without any traction, thus preventing unintended tears. Our case series demonstrated that PEAK-fc, in a safe and rapid manner, allows surgeons to perform traction-free and controlled capsulotomies, even in cases of massive pigment deposition on the lens capsule. Cuts with PEAK-fc showed almost no thermal damage at the edges of the tissue.

A major advantage of PEAK-fc is the short learning curve. Except for one surgeon (SGP), who had carried out prior animal studies and vitreoretinal studies in humans, none of the other surgeons participating in the present case series was experienced with PEAK-fc technology. Before surgery of complicated anterior segment cases, surgeons were instructed 
orally and by a video demonstration. This confirms that PEAKfc indeed increases the safety of surgery in the specific manoeuvres described without the need of practice on cadaver or animal eyes.

Other devices for anterior capsulotomy, such as ERBEDIACAPSUTOM high-frequency capsulotomy, ${ }^{15} 16$ and the recently introduced Fugo Blade, have been associated with a higher risk for capsule tears and intraoperative and postoperative complications than CCC..$^{17-20}$ Vitrectorhexis, ${ }^{21}$ another procedure for anterior capsulotomy, preferentially used in paediatric cataract surgery, showed radial tears in $7.7 \%$ of cases. $^{19}$ Additionally, in contrast to PEAK-fc, vitrectorhexis requires a long learning curve. This is a major advantage of PEAK-fc, as only a few cases of paediatric cataract surgery are usually performed by one surgeon during a year.

PEAK-fc allowed for excision of anterior capsule phimosis and dissection of iris synechiae, while damage of lens capsules and iris vessels was avoided and the risk of bleeding minimised. However, even if intraoperative bleeding occurred, it could immediately be stopped using PEAK-fc's coagulation mode without having to remove the instrument, as required during conventional surgery. As opposed to PEAK-fc, all conventional techniques available for separation of posterior iris synechiae have an increased risk of complications such as capsule damage and uncontrolled bleeding in the iris vessels.

One side effect of PEAK-fc is the formation of gas bubbles, potentially impairing the surgeon's view of the operating field. The amount of gas bubbles generated by PEAK-fc can be compared with the gas development in conventional intraocular diathermy. However, in the present study, in none of the performed procedures did the development of gas impair vision to such a degree as to make surgery unsafe or impossible.

In summary, PEAK-fc was successfully used for a variety of surgical manoeuvres commonly encountered in patients undergoing complicated anterior segment surgery. PEAK-fc allowed for surgical cutting in a very precise manner, resulting in reproducible and reliable dissection, with induction of only minimal collateral damage at the edges of the cut.

\section{ACKNOWLEDGEMENTS}

We thank Harald Kroehn for expert technical assistance.

\section{Authors' affiliations}

Siegfried G Priglinger, Claudia S Alge, Thomas C Kreutzer, Christos Haritoglou, Martin Grueterich, Anselm Kampik, Department of Ophthalmology, Ludwig-Maximilians-University, Munich, Germany

Daniel Palanker, Department of Ophthalmology and Hansen Experimental Physics Laboratory, Stanford University, Stanford, California, USA
Funding: Part of this project (Stanford University) was provided by the $\mathrm{NIH}$ RO1 EYO1 288 grant, and by the Whitaker Foundation grant RG-03-0042.

Competing interests: DP has patent-related financial interest in PEAK.

Part of this work has been presented at the ESCRS 2005 and at ARVO 2006.

\section{REFERENCES}

1 Palanker DV, Miller JM, Marmor MF, et al. Pulsed electron avalanche knife (PEAK) for intraocular surgery. Invest Ophthalmol Vis Sci 2001;42:2673-8.

2 Palanker DV, Marmor MF, Branco A, et al. Effects of the pulsed electron avalanche knife on retinal tissue. Arch Ophthalmol 2002;120:636-40.

3 Miller JM, Palanker DV, Vankov A, et al. Precision and safety of the pulsed electron avalanche knife in vitreoretinal surgery. Arch Ophthalmol 2003;121:871-7

4 Palanker D, Vankov A, Bilbao K, et al. Optimization of the pulsed electron avalanche knife for anterior segment surgery. Ophthalmic Technol SPIE 2003;4951:56-61

5 Priglinger SG, Haritoglou C, Palanker D, et al. Pulsed electron avalanche knife (PEAK-fc) for dissection of retinal tissue-clinical and histological findings. Arch Ophthalmol 2005;123:1412-18.

6 Priglinger SG, Haritoglou C, Mueller A, et al. Pulsed electron avalanche knife (PEAK-fc) in vitreoretinal surgery. Retina 2005;25:889-96.

7 Shepherd JR. In situ fracture. J Cataract Refract Surg 1990;16:436-40.

8 Horiguchi M, Miyake K, Ohta I, et al. Staining of the lens capsule for circular continuous capsulorrhexis in eyes with white cataract. Arch Ophthalmol, $1998 ; 116,535-7$.

9 Melles GRJ, de Waard PWT, Pameyer JH, et al. Trypan blue capsule staining to visualize the capsulorhexis in cataract surgery. J Cataract Refract Surg, 1999;25, 7-9.

10 Walkow T, Anders N, Klebe S. Endothelial cell loss after phacoemulsification: relation to preoperative and intraoperative parameters. J Cataract Refract Surg 2000;26:727-32.

11 Bourne RR, Minassian DC, Dart JK, et al. Effect of cataract surgery on the corneal endothelium: modern phacoemulsification compared with extracapsular cataract surgery. Ophthalmology 2004;111:679-85.

12 Wilson ME, Bluestein EC, Wang XH, et al. Comparison of mechanized anterior capsulectomy and manual continuous capsulorhexis in pediatric eyes. J Cataract Refract Surg 1994;20:602-6.

13 Izak AM, Werner L, Pandey SK, et al. Analysis of the capsule edge after Fugo plasma blade capsulotomy, continuous curvilinear capsulorhexis, and canopener capsulotomy. J Cataract Refract Surg 2004;30:2606-11.

14 Neuhann T. Theorie und Operationstechnik der Kapsulorhexis. Klin Monatsbl Augenheilkd, 1987; 190, 542-5.

15 Klöti R. Vordere Hochfrequenz (HF)-Kapsulotomie. I. Experimentelle Studie. Klin Monatsbl Augenheilkd 1992;200:507-10.

16 Krag S, Thim K, Corydon L. Diathermic capsulotomy versus capsulorhexis: a biomechanical study. J Cataract Refract Surg 1997;23:86-90.

17 Nepp J, Amon M, Grössing A, et al. Inzidenz intraund postoperativer Komplikationen nach Kapsulorhexis und Hochfrequenz-Kapsulotomie. Spektrum Augenheilkd, 1996;10, 60-2.

18 Kruger A, Amon M, Nepp J. Intraoperative and postoperative complications of high-frequency capsulotomy and continuous curvilinear capsulorhexis. J Catarac Refract Surg 1997;23:429-32

19 Wilson ME Jr. Anterior lens capsule management in pediatric cataract surgery. Trans Am Ophthalmol Soc 2004;102:391-422.

20 Izak AM, Werner L, Pandey SK, et al. Analysis of the capsule edge after Fugo plasma blade capsulotomy, continuous curvilinear capsulorhexis, and canopener capsulotomy. J Cataract Refract Surg 2004;30:2606-11.

21 Wilson $\mathrm{ME}$, Bluestein EC, Wang XH, et al. Comparison of mechanized anterior capsulectomy and manual continuous capsulorhexis in pediatric eyes. J Catarac Refract Surg 1994;20:602-6. 